\title{
External Morphology of the Adult of Heraclides anchisiades capys (Hübner, [1809]) (Lepidoptera - Papilionidae) III. Abdomen
}

\author{
Luis Anderson Ribeiro Leite ${ }^{*}$, Mirna Martins Casagrande ${ }^{1}$ and Olaf Hermann Hendrik \\ Mielke ${ }^{1}$ \\ Departamento de Zoologia; Setor de Ciências Biológicas; Universidade Federal do Paraná; C. P.: 19020; 81531- \\ 980; Curitiba - PR - Brasil
}

\begin{abstract}
The purpose of this study was to highlight the morphological components of the abdomen of the adults of Heraclides anchisiades capys (Hübner, [1809]), seeking a comparative focus with other Papilionoidea and Hesperioidea. The most relevant morphological characters were: absence of post-espiracular bar in both the sexes, presence of superuncus in the males as a projection of the eighth tergum and saccus with a posterior projection, bursa copulatrix with approximately 2.3 times the length of the ductus bursae in the females.
\end{abstract}

Key words: Citrus, Neotropical, Papilioninae, Papilionoidea

\section{INTRODUCTION}

According to Scoble (1992), the abdomen constitutes the more obviously segmented part of insects, which holds the genitalia, whose structures are of great interest for the taxonomy of Lepidoptera. The basic structure of the male and female genitalias is described, while separately from its obvious function, the precise mechanisms of its particular parts are relatively less known. The morphology of the female genitalia has been important in less specific levels of taxonomic divisions in Lepidoptera, while the male genitalia is commonly used taxonomically in more specific levels as genus and specie. The pregenital structures also offer important characters, particularly those that form the base of the abdomen and its connection with the thorax. This region has been important for the phylogenetic reconstruction and, very often, neglected morphologically as opposed to the genital characters.

Papilionidae is a very diverse group and the morphological characters studied are sometimes unsatisfactory. Some studies have been made on the structures of the male genitalia and in particular the valvae, justifying its morphological importance when the phylogenetic relations are determined (Hancock, 1983; Miller, 1987; Tyler et al., 1994). Srivastava (1965) described the male genitalia as a structure that still leads to controversial results for the morphology of Lepidoptera. Several studies have been done on the morphology of the abdomen of Lepidoptera, but the focus has been only in the genitalia and the pregenital structures have not been studied (Banks et al., 1976; Callaghan, 1997; Kuznetzov and Stekol'nikov, 2001; Hall and Harvey, 2002; Hall,

*Author for correspondence: madison.2@ig.com.br 
2003; Hall and Callaghan, 2003). For the family Papilionidae, the studies of Miller (1987) and Hancock (1983) also focused on the genital structures only. The study by Srivastava (1965) focused on the muscular abdominal system, justifying the existing negligence on the studies of musculature of the abdomen and genitalia.

The aim of this work was to study the external morphology of Heraclides anchisiades capys (Hübner, [1809]), highlighting the components of the abdomen aiming to contribute to the comparison with other Papilionoidea and Hesperioidea.

\section{MATERIALS AND METHODS}

The origin of the material, as well as the treatment of the structures and preparation of the illustrations followed the same methodology as described earlier (Leite et al., 2010). For the study of the genitalia, the abdomen was laterally positioned and opened through a longitudinal cut on the pleural region.

For the pregenital abdominal structures, the terminology used was as described by Srivastava (1965). For the genitalia of both sexes, the main terminology used was adopted from Klots (1956) and Miller (1987) with adaptations (Oiticica Filho, 1946; Ehrlich, 1958a, b, 1960; Casagrande, 1979; Sorensen, 1980; Bilotta, 1994; Bizarro et al., 2003; Mielke et al., 2004; Duarte, 2007; Mielke et al., 2008), in addition to classic studies on morphology (Snodgrass, 1935; Matsuda, 1976).

\section{RESULTS}

\section{Pregenital structures}

Abdomen composed by 10 segments, the two last ones are modified in the males, giving origin to the structures of the genitalia, whereas in the females, the three last ones are modified. The females' abdomen is more extended dorsoventrally in comparison to the males (Figs 1, 2, 8, 9).

On both sexes, the first segment presents modifications in its sclerites, relative to the merger of the metathorax's posterior region. Tergum I with membranous anterior third, the remainder being sclerotized and rectangular. Ventrally to the latest, the laterotergite, as a narrow sclerite and anteriorly projected, with a subtriangular shape on males and subrectangular with a small posteroventral projection on females. Sternum I anterior to the first spiracle, slender and anteriorly projected towards the anteromedialy region of the abdomen and posteriorly articulated to the anterodorsal extremity of the sternum II.

Tergum VII on males narrower in comparison with the others and tergum VIII with posterior slender projection forming the superuncus. On females, tergum VIII narrower in comparison with the others. Rectangular sternum VIII, the last one observed on males before the genital elements, while on females the sternum VII is the last and oval shaped.

\section{Male genitalia}

Dorsally limited by the eighth tergum, projected medium-posteriorly in a dorsoventrally curved "hook" shaped structure, called superuncus. Tegumen representing the tergum IX, ventromedially to the tergum VIII, anteriorly fused to the uncus, the latest a modification of the tergum $\mathrm{X}$, triangular and with distal projection ventrally curved. Gnathos articulated to the posterior margin of the tegumen, modification of the tenth sternum, as a ventral sclerite, projected in the caudal direction and with dorsal bristles. Transtilla reduced to a couple of slender structures, with absent median region, and articulated on the dorsoproximal angle of the valvae. Fultura inferior, narrow sclerotized structure in the shape of an "U", ventrally situated, supporting the aedeagus and visible only on posterior view (Figs 3-7).

The genitalia is limited in its ventral portion by the saccus, modification of the ninth sternum with the arm of the saccus projected anterodorsally as a narrow sclerotized band that reaches the ventral arm of the tegumen, forming an arch.

Medium-laterally flattened valvae, forming a couple of plates articulated to the transtilla in the region of the costa and to the ventral arms of the tegumen and dorsal of the saccus on the region of the sacculus. The valvae presents the harpe in its central portion, with a group of differentiated bristles in anterodorsal position, a dentated posterior edge and is strongly sclerotized in comparison with the other regions.

Cylindrical aedeagus, with anterior third strongly sclerotized and posterior third with distal slit laterally. Terminal bulbus ejaculatorius, being the place of passage of the ductus ejaculatorius. Distally the vesica is observed without cornutus, remaining retracted while resting. 


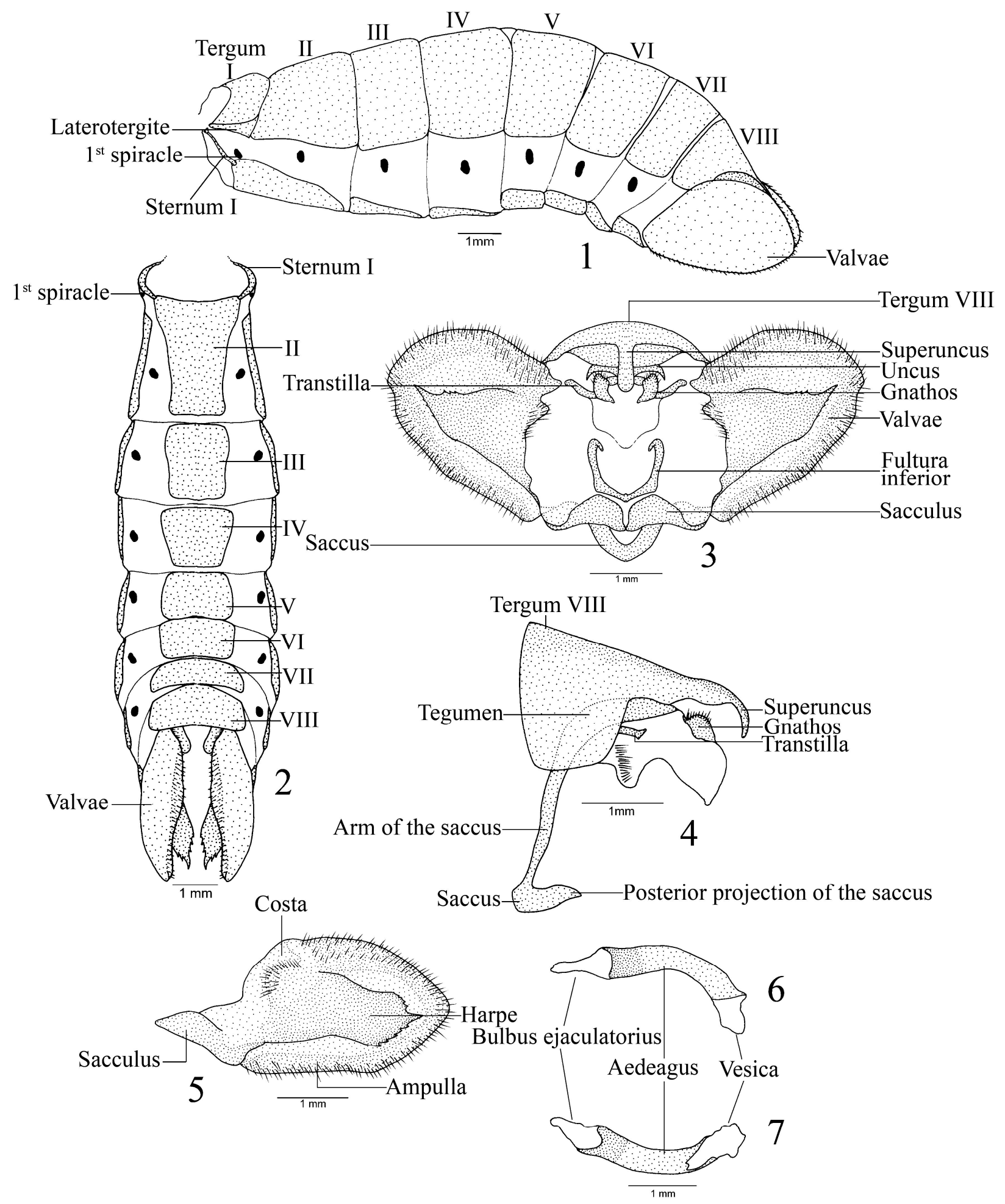

Figures 1 - 7 - Heraclides anchisiades capys: male abdomen. 1 - 2 - pregenital segments: 1 lateral view. 2 - ventral view: 3 - 7 - male genitalia: 3 - posterior view. 4 - lateral view. 5 - valvae. 6 - 7 - aedeagus: 6 - anterior view. 7 - posterior view. 

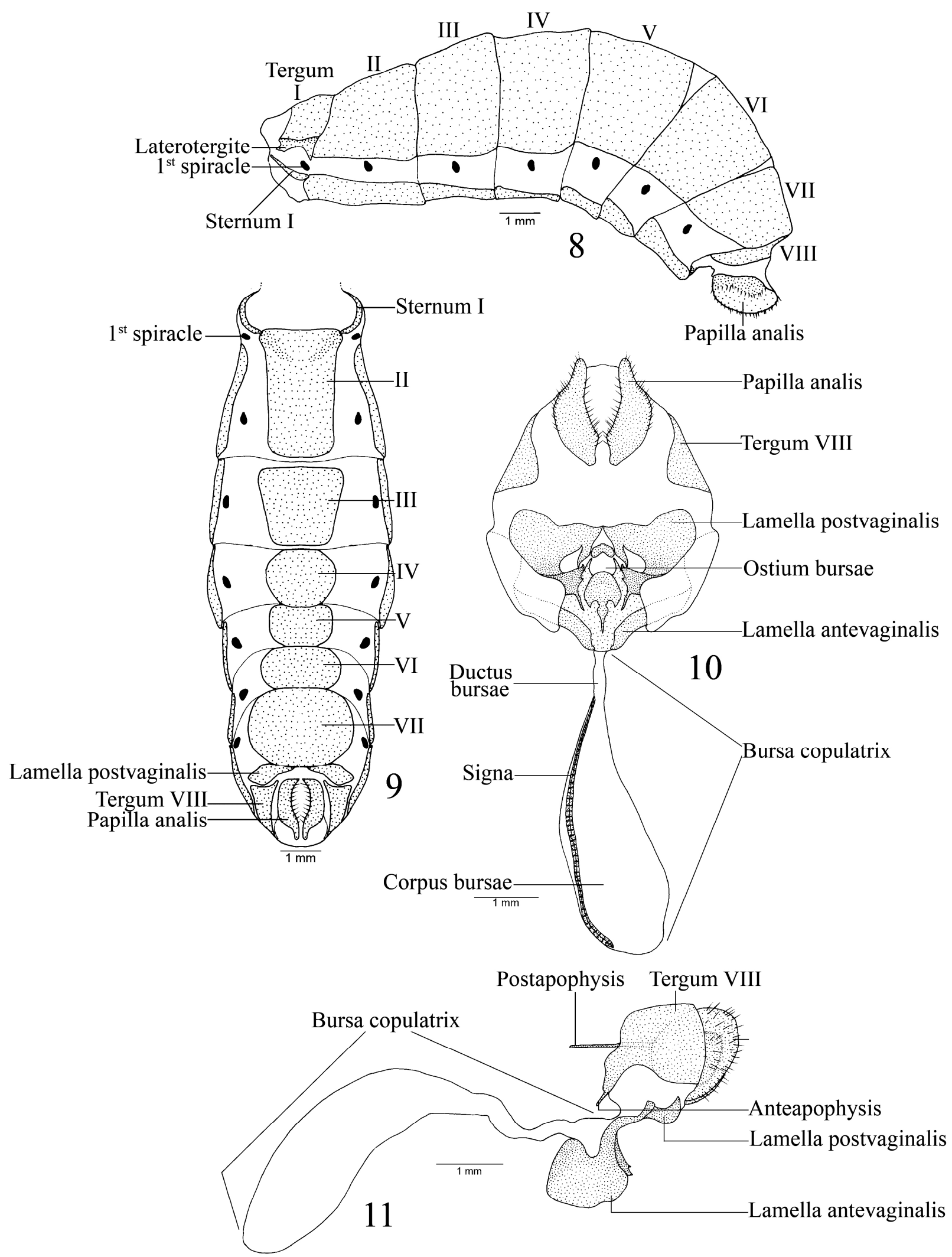

Figures 8 - 11- Heraclides anchisiades capys: female abdomen. 8 - 9 - pregenital segments: 8 lateral view. 9 - ventral view: 10 - 11 - female genitalia: 10 - ventral view. 11 lateral view. 


\section{Female genitalia}

Constituted by the eighth, ninth and tenth modified abdominal segments. Tergum VIII with anteroventral projection in both sides, forming the anteapophysis, and tergum IX $+\mathrm{X}$ forming the papilla analis, these two being vertical plates posteromedially located on the abdomen, with partial sclerotinization and countless bristles distributed in the surface. Postapophysis as a couple of anterolateral projections of the papilla analis (Figs 10, 11).

Sternum VIII represented by two genital plates, the lamella antevaginalis is anteriorly and the lamella postvaginalis is posteriorly located, and between these the ostium bursae opens.

Bursa copulatrix formed by the ostium, ductus and corpus bursae. The ductus bursae begins in the ostium, and is inserted in the bursa copulatrix, the last one being membranous and saculiform shaped, presenting only one ventrolaterally left signa that occupies all its length. The bursa copulatrix has approximately 2.3 times the length of the ductus.

\section{DISCUSSION}

Ehrlich (1958b) reported the absence of the postespiracular bar in Papilionidae, which is corroborated in the present study. Nevertheless, regarding the pre-espiracular bar, the same author said to be absent only in Pieridae and did not comment on the condition of the same bar in the distinct groups. In the present study, the preespiracular bar is indistinct in the region; only the first sternum is visualized as found by Srivastava (1965). Bilotta (1994) did not mention the preespiracular bar in Morphinae (Nymphalidae) however, the sclerite has been found in other Nymphalidae (Ehrlich, 1958a; Casagrande, 1979; Bizarro et al., 2003; Mielke et al., 2004). On the other Papilionoidea and Hesperioidea morphologically studied, the pre-espiracular bar has not been present.

The superuncus has been, up to the present study, a synapomorphy just for Papilioninae; however, Miller (1987) observed similar structure in Colias philodice Godart, 1819 (Lepidoptera - Pieridae). This sclerite appears in several systematic studies regarding the family, presented under singular forms, including the specie in the study. This has been, in general, in totally different forms for each species in the Papilionidae (Srivastava, 1965; Hancock, 1983; Miller, 1987; Tyler et al., 1994).
Similar was observed for the other structures of the male genitalia of great taxonomic importance, by the peculiarities presented in these studies for each species, such as the cases of the transtilla, gnathos, fultura inferior and valvae.

The projection of the saccus in the studied specie is posterior, therefore, opposite to the other Papilionoidea previously studied where it has been reported as anterior (Casagrande, 1979; Bilotta, 1994; Bizarro et al., 2003; Mielke et al., 2004).

In the females, the bursa copulatrix is structurally very distinct amongst the species of Papilionidae and the other Papilionoidea and Hesperioidea. Form, number, position and size of the signa of the bursa copulatrix on the different species observed on the studies of this structure within the family (Munroe, 1961; Hancock, 1983; Miller, 1987) and in other groups (Ehrlich, 1960; Casagrande, 1979; Hall, 2001; Penz and Devries, 2006; Duarte, 2007) show that they are of significant taxonomic relevance.

\section{REFERENCES}

Banks, H. J.; Holloway, J. D. and Barlow, H. S. (1976), A revision of the genus Ptychandra (Lepidoptera Nymphalidae). Bull. Br. Mus. (Nat. Hist.) Entomol., 32, 217 - 252.

Bilotta, I. G. (1994), Morfologia Comparada do Abdome das Espécies Sulbrasileiras de Morphinae (Lepidoptera: Nymphalidae). Rev. Bras. Zool., 11 (4), $737-748$.

Bizarro, J. M. S; Casagrande, M. M. and Mielke, O. H. H. (2003), Morfologia externa de Thyridia psidii cetoides (Rosenberg and Talbot) (Lepidoptera, Nymphalidae, Ithomiinae). III. Abdome e apêndices. Rev. Bras. Zool., 20 (4), 681 - 684.

Callaghan, C. J. (1997), A review of the genus Panara Doubleday, 1847 (Riodinidae) in southeast Brazil, with a description of two new subspecies. J. Res. Lepid., 34, 21 - 38.

Casagrande, M. M. (1979), Sobre Caligo beltrao (Illiger). IV: Morfologia externa do adulto - abdome. (Lepidoptera, Satyridae, Brassolinae). Rev. Bras. Biol., 39 (3), 711 - 716.

Duarte M. (2007), Morfologia externa do adulto de Hemiargus hanno (Stoll) (Lepidoptera, Lycaenidae, Polyommatinae, Polymmatini) II. Região cervical, tórax e abdome. Iheringia, Sér. Zool., 97 (2), 194 206.

Ehrlich, P. R. (1958a), The integumental anatomy of the monarch butterfly Danaus plexippus L., (Lepidoptera: Danaidae). Univ. Kansas Sci. Bull., 38, 1315 - 1349. 
Ehrlich, P. R. (1958b), The comparative morphology, phylogeny, and the higher classification of the butterflies (Lepidoptera, Papilionoidea). Univ. Kansas Sci. Bull., 39, 305 - 370.

Ehrlich, P. R. (1960), The integumental anatomy of the silver-spotted skipper, Epargyreus clarus Cramer (Lepidoptera - Hesperiidae). Microentomology., 24, 1 $-23$.

Hancock, D. L. (1983), Classification of the Papilionidae (Lepidoptera): A phylogenetic approach. Smithersia., 2, 1 - 48.

Hall, J. P. W. (2001), A revision of the new riodinid butterfly genus Dachetola (Lepidoptera: Riodinidae). J. N. Y. Entomol. Soc., 109 (2).

Hall, J. P. W. (2003), Phylogenetic reassessment of the five forewing radial-veined tribes of Riodininae (Lepidoptera: Riodinidae). J. R. Entomol. Soc., 28, 23 - 37.

Hall, J. P. W. and Callaghan, C. J. (2003), A revision of the new riodinid butterfly genus Pseudotinea (Lepidoptera: Riodinidae). J. Nat. Hist., 37: 821 837.

Hall, J. P. W. and Harvey, D. J. (2002), Basal subtribes of the Nymphidiini (Lepidoptera: Riodinidae): phylogeny and myrmecophily. Cladistics., 18 (4), 539 $-569$.

Klots, A. B. (1956), Lepidoptera, pp. 97 - 110. In S. L. Tuxen [ed.], Taxonomists' glossary of genitalia in insects. Munksgaard, Copenhagen, Denmark. 283 p.

Kuznetzov, V. I. and Stekol'nikov, A. A. (2001), Comparative Morphology of Male Genitalia in the Subfamilies Morphinae and Brassolinae and Resurrection of the Family Satyridae, status resurr. (Lepidoptera), in a New Sense. Entomol. Rev., 81 (4), $381-392$.

Leite, L. A. R; Casagrande, M. M. and Mielke, O. H. H. (2010). External Morphology of the Adult of Heraclides anchisiades capys (Hübner, [1809]) (Lepidoptera - Papilionidae). I. Head, cephalic appendages and cervical region. Braz. Arch. Biol. Technol, 53 (5), 1119 - 1126.

Matsuda, R. (1976). Morphology and Evolution of the Insect Abdomen. Oxford, Pergamon Press, VIII + $534 \mathrm{p}$.
Mielke, C. G. C.; Mielke, O. H. H. and Casagrande, M. M. (2004), Estudo comparado de morfologia externa de Zaretis itys itylus (Westwood) e Agrias claudina annetta (Gray). (Lepidoptera, Nymphalidae, Charaxinae) III. Abdome. Rev. Bras. Zool., 21 (4), 905 - 912.

Mielke, O. H. H.; Austin, G. T. and Warren, A. D. (2008). A new Parelbella from Mexico (Hesperiidae: Pyrginae: Pyrrhopyrgini). Fla. Entomol., 91 (1), 30 35.

Miller, James S. (1987), Phylogenetic studies in the Papilioninae (Lepidoptera: Papilionidae). Bull. Am. Mus. Nat. Hist., 186, 365 - 512.

Munroe, E. G. (1961), The classification of the Papilionidae (Lepidoptera). Can. Entomol., Supplement, 17: 1 - 51.

Oiticica, J. F. (1946), Sobre a morfologia do pênis em Lepidoptera. Bol. Mus. Nac., 50, 1 - 79.

Penz, C. M. and Devries, P. J. (2006), Systematic position of Apodemia paucipuncta (Riodinidae), and a critical evaluation of the Nymphidiine transtilla. Zootaxa., 1190, 1 - 50.

Scoble, M. J. (1992), The Lepidoptera : form, function and diversity. Natural History Museum Publications. Oxford University Press, 404p.

Snodgrass, R. E. (1935), Principles of insect morphology. McGraw-Hill Book Company. New York and London. 667 pp., 319 figs.

Sorensen, J. T. (1980), An integumental anatomy for the butterfly Glaucopsyche lygdamus (Lepidoptera: Lycaenidae): a morphological terminology and homology. Zool. J. Linn. Soc., 70, 55 - 101.

Srivastava, K. P. (1965), Studies on the lemon butterfly Papilio demoleus L. (Lepidoptera). Part V. Skeleto muscular system of the abdomen. Zool Anz., 177, 217 - 236.

Tyler, H.; Brown, K. S. and Wilson, K. (1994), Swallowtail Butterflies of the Americas - A Study in Biological Dynamics, Ecological Diversity, Biosystematics, and Conservation. Scientific Publishers, Gainesville.376p.

Received: November 12, 2009; Revised: August 18, 2010; Accepted: January 05, 2011. 